\title{
Aktuelle Nachrichten
}

medgen $2018 \cdot 30: 304$

https://doi.org/10.1007/s11825-018-0192-4

Online publiziert: 4. Juli 2018

(c) Springer Medizin Verlag GmbH, ein Teil von Springer Nature 2018

Liebe Kolleginnen und Kollegen,

wir laden Sie sehr herzlich ein zur 32. Tumorgenetischen Arbeitstagung nach Bad Ischl im Salzkammergut.

Franz de Paula Augustin Wirer war Hofarzt am Wiener Hof und Leibarzt von Kaiser Franz I. sowie Lehrer an der Wiener Medizinischen Schule und Rektor der Wiener Universität. Wirer nutzte die Heilwirkung der Sole und begründete durch den Aufbau des ersten österreichischen Solekurbades den Weltruf von Bad Ischl.

Den Höhepunkt der Ischler Blütezeit bildete die Zeit von 1849 bis 1914 als kaiserlicher Sommerresidenz unter Kaiser Franz Joseph I und seiner Gemahlin Kaiserin Elisabeth (Sissi). Am Freitag gibt es die Möglichkeit, die Kaiserstadt und den Kurort kennenzulernen. Nach einer Führung durch die Kaiservilla findet in der Trinkhalle, einer unter Denkmalschutz stehenden ehemalige Kuranlage, die Abendveranstaltung statt. Wo früher Trinkkuren mit Molke verabreicht wurden, werden wir uns beim Fachsimpeln kulinarisch und musikalisch verwöhnen lassen.

Das wissenschaftliche Programm wird wie immer aus Übersichtvorträgen, Vorträgen über aktuelle Forschungsarbeiten, aus Fallbeispielen und Industrie-Präsentationen bestehen.

Im MTA-Workshop wollen wir die Tipps und Tricks für die Praxis zum Leben erwecken. Interdisziplinarität: rasante Fortschritte in der Medizin machen eine Zusammenarbeit der einzelnen Fächer notwendiger denn je. Fachärztinnen und Fachärzte für Humangenetik/ Medizinische Genetik, für Innere Medizin und Pädiatrie mit Schwerpunkt Hämatologie/Onkologie, für alle anderen Fächer mit onkologischen Fragestellungen und für die Pathologie - sie alle sind gefragt, in Zusammenarbeit mit unseren Fachhumangenetikerinnen in einem engmaschigen Netzwerk zum Wohle der Tumorpatientinnen und Tumorpatienten beizutragen.

Wir freuen uns auf Ihr Kommen.

\section{Gerald Webersinke \& Hans-Christoph Duba}

\section{Tagungsort}

Kongress \& Theaterhaus

Kurhausstraße 8

4820 Bad Ischl

Österreich

\section{Tagungsleitung}

Dr. rer. nat. Gerald Webersinke Labor für Molekularbiologie und Tumorzytogenetik, Ordensklinikum Linz Barmherzige Schwestern

Doz. Dr. med. Hans-Christoph Duba Institut für Medizinische Genetik, Kepler Universitätsklinikum Linz

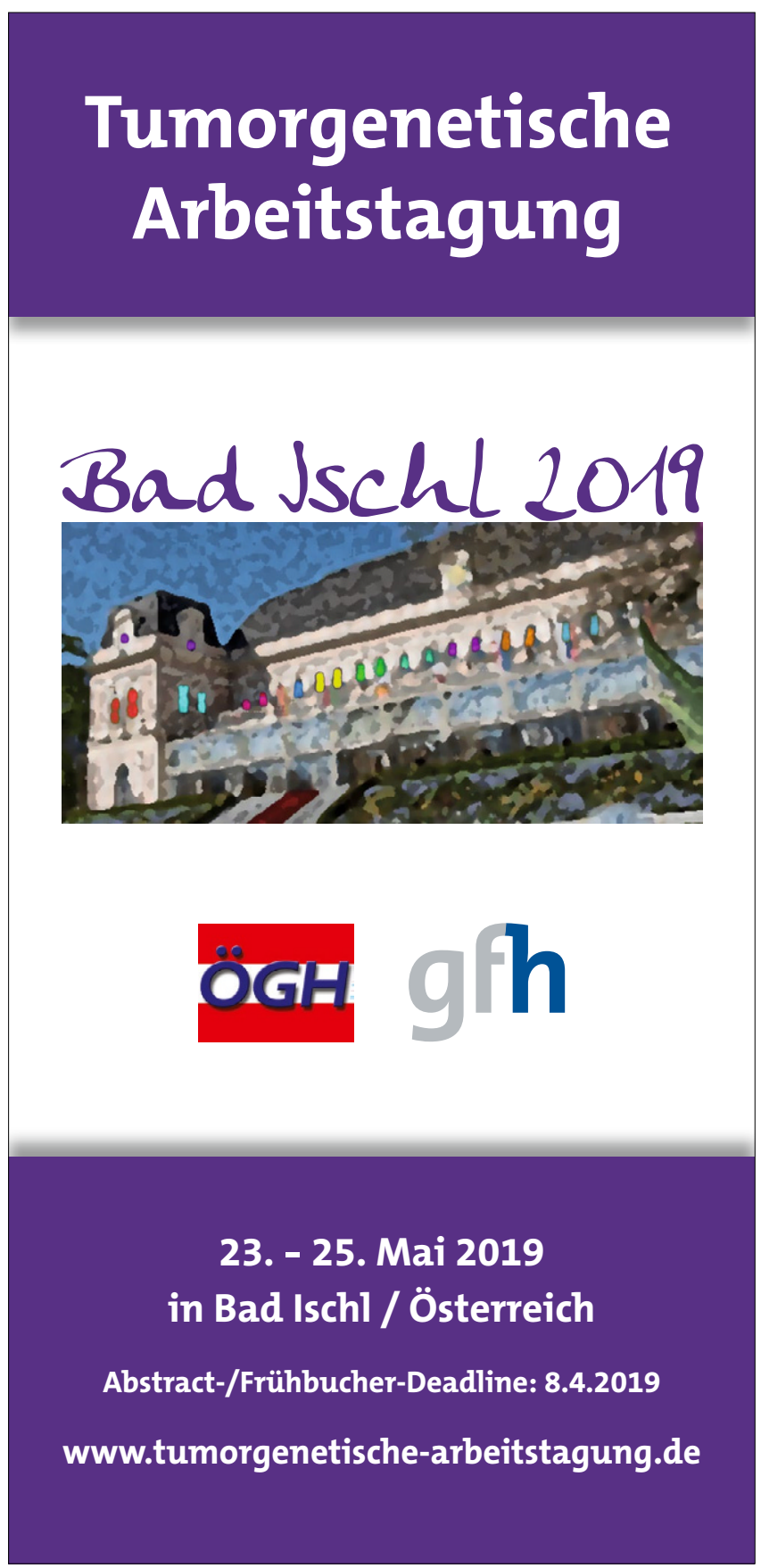

